\title{
Does Human Stick on Reference Price (Anchoring Bias)? A Social Experiment on Tourism Sector
}

\author{
Ekrem Tufan ${ }^{1}$, Merve Aycan ${ }^{2}$, Yonca İmer ${ }^{3}$, Bahattin Hamarat ${ }^{4}$. Erol Duran \\ Çanakkale ${ }^{5}$
}

\begin{abstract}
:
Contrary to Traditional Economics, Behavioural Economics postulates that people are not always rational. Dan Ariely (2010) says “...we are not only irrational but predictable irrational-that our irrationality happens the same way, again and again..."

In literature we call them as biases. There are many biases such as overconfidence, framing effect, sunk cost effect, gambler fallacy etc. reference point bias is one of them.

This article examines the case of reference price in the tourism sector as a social factor trying to explain if this characteristic creates a bias in the final decision of the uses.
\end{abstract}

\footnotetext{
${ }^{1}$ Onsekiz Mart University, Faculty of Tourism, Ekrem Tufan [etufan@yahoo.com]

${ }^{2}$ Onsekiz Mart University, Faculty of Tourism

${ }^{3}$ Onsekiz Mart University, Faculty of Tourism

${ }^{4}$ Onsekiz Mart University, Faculty of Tourism

${ }^{5}$ Onsekiz Mart University, Faculty of Tourism
} 


\section{Introduction}

Before explaining biases let's give more information about different views of Traditional and Behavioural Economics approaches about rationality. As human beings we face life's daily basic and difficult problems like making choices, decision making, solving problems etc. Do we chose/decide/solve problems rationally?

Traditional and Behavioural Economics theories dissociate at human rationality. Liu E. and Nick Hanauer, (2016, p.1) describes Traditional Economics as ...at the simplest level, traditional theory assumes economies are linear systems filled with rational actors who seek to optimize their situation. Outputs reflect a sum of inputs, the system is closed, and if big change comes it comes as an external shock. The system's default state is equilibrium...Human rationality means two things.

When they receive new information, agents update their beliefs correctly, in the manner described by Bayes' law. Second, given their beliefs, agents make choices that are normatively acceptable, in the sense that they are consistent with Savage's notion of Subjective Expected Utility (SEU) (Barberis and Thaler, 2002, p.2). On the other hand, we know that human beings could not been always fully rational. Full rationality requires unlimited cognitive capabilities. Fully rational man is a mythical hero who knows the solutions of all mathematical problems and can immediately perform all computations, regardless of how difficult they are. Human beings are very different. Their cognitive capabilities are quite limited. For this reason alone the decision behavior of human beings cannot conform to the ideal of full rationality (Selten R. 1999, p.3).

So if we know human cannot be fully rational what can we call her/him? We call her/him as bounded rational. Bounded rationality means, “...individuals do not seek to maximise their benefit from a particular course of action (since they cannot assimilate and digest all the information that would be needed to do such a thing). Not only can they not get access to all the information required, but even if they could, their minds would be unable to process it properly. The human mind necessarily restricts itself..." (The Economist, 2009, p.1).

Because many theories based on it such as Efficient Market Hypothesis rationality assumption is very important. However in the literature there are many evidences against rationality assumption and Efficient Market Hypothesis. Heuristics (mental short cuts) and biases are good examples of this.

In daily life people tend to learn and keep in mind numbers. That numbers are very effective when they make their decisions and we call it as reference point. Reference point creates anchoring effect. An anchor is a price point that gives you an idea of how much something should cost. The trouble with anchoring is that it is very difficult to ignore. Once you have a set price of something in mind, it can be tough 
to remember that the anchor you've been using might not have anything to do with a rational price you want to spend (Birken E. G., 2016, p.1). If these numbers are related with the subject which you have to make your decision is good but what about if there is no relation? Dan Airely and George Loewenstein (Airely, ibid, p.33) have done an experiment with MIT MBA students. They asked them to jot down last two digits of their social security numbers and tell whether they would pay this amount for a number of products. They reported that students with social security numbers ending in the upper 20 percent placed bids that were 216 to 346 percent higher than those of the students with social security numbers ending in the lowest 20 percent. This is anchoring. The students have anchored on last two digits of their social security numbers. Of course this is not a rational behavioural.

Cognitive psychologists have documented many patterns regarding how people behave. Some of these patterns are as follows (Ritter Jay R., 2003, p.430): Heuristics, overconfidence, mental accounting, framing, representativeness, anchoring (conservatism) and disposition effect. Anchoring (reference point) bias could be explained as when things change, people tend to be slow to pick up on the changes. In other words, they anchor on the ways things have normally been. The conservatism bias is at war with the representativeness bias (Ritter Jay R. ibid, p.432).

Reference point (anchoring) bias can be observed in every market regardless of the country. Chang et all. (2016, p.55) have searched anchoring bias in real estate market. They have tested the proposition that when estimating real estate prices, market participants are likely to be affected by anchoring bias. The researchers report that increased uncertainty in housing prices leads to an upward bias in the beliefs of buyers with regard to pricing distribution, with our study contributing to the extant literature through several interesting empirical findings. Another founding is that anchoring is a common phenomenon among buy-side investors, regardless of gender.

This bias has also been observed in financial markets. Baker et all. (2012, p.49) have searched if prior stock price peaks of targets affect several aspects of merger and acquisition activity. They reports that offer prices are biased toward recent peak prices although they are economically unremarkable. Conversely, bidder shareholders react more negatively as the offer price is influenced upward toward a peak.

Becker-Peth and Ulrich W. Thonemann (2016, p.1033), have investigated if there is reference point bias (anchoring) at human inventory decisions or not? They claim that these decisions deviate from classical normative predictions, and it has been found evidence for reference-dependent valuation of human decision makers.

Meub and Till E. Proeger (2015, p.29) have applied social experiment to search anchoring in social context. The researchers claim that the research results support 
the assumption that anchoring remains a valid explanation for systematically biased decisions within market contexts.

The paper organized as follows: Data and methodology explains how data has been collected and describes the methodology. In the empirical results part, results of experiment as tables have been given. Last part is the conclusion and makes critics about the results.

\section{Data and Methodology}

In this study, it has been created a scenario about reference point bias which inspired Daniel Kahneman's Thinking Fast and Slow book (2011) and some other behavioural economics articles and applied two groups. First group was our control group and they were 150 university students at three different faculties of Canakkale Onsekiz Mart University. Second group respondents have been chosen randomly and they were 470 people from different cities of Turkey with different ages, income levels and genders. Other than age, education, income and gender we also searched if tourism education and tourism related work have an effect on reference point (anchoring) bias.

A scenario is a methodology that collects data about current situation to perceive and describe for potential changings of a specific subject in the future. Hypothesized for the future with scenarios which are envisaged either imaginary or real, provide a basis for taking precautions and foresee possible results (Kozak 2014, p.105). In the literature there are some researches that investigated biases including reference point have been searched for some sectors but we could not find biases researches on tourism sector. So we decided to create a scenario and we have inspired from Kahneman's book namely Thinking Fast and Slow.

The example from the book which is given below is especially interesting for us. Let's consider these two questions (Kahneman, ibid, p.122):

Was Gandhi more or less than 144 years old when he died?

How old was Gandhi when he died?

What about your answer? Was it close to 144 ? Correct answer was 78 years. Many people stick given number 144 and estimate a close number of it. Because of that we decided to give a reference point(s) (anchoring number) and searched if people stick it/them.

Then we pre-tested it in our Tourism Faculty and made some small corrections. The scenario was fictionalised as follows: 
Question 1: A friend of yours informed you that she/he went on a holiday to Antalya in June and paid 100 Turkish Lira (TL) for bed and breakfast. In the meantime Ministry of Turkish Tourism and Culture announced a statistics that average price for hotel rooms located in exactly the same area where your friend stayed hotel rate was 200 TL. You would like to go same area for holiday in July but happens to be at the same date with one of the national festivals (bayram). What is the acceptable price for you? We expect that people take arithmetic average of given two prices and mostly reply it as around $150 \mathrm{TL}$.

Question 2: A friend of yours informed you that she/he went on a holiday to Antalya in June and paid 200 Turkish Lira (TL) for bed and breakfast. In the meantime Ministry of Turkish Tourism and Culture announced a statistics that average price for hotel rooms located in exactly the same area where your friend stayed hotel rate was 200 TL. You would like to go same area for holiday in July but happens to be at the same date with one of the national festivals (bayram). What is the acceptable price for you? We expect that people will stick the price (200 TL) and reply it as around $200 \mathrm{TL}$.

Question 3: Last year a friend of yours went on a holiday to Antalya in June and paid 100 Turkish Lira (TL) for bed and breakfast. In the same month another friend of yours also accommodated a hotel in same area and paid $150 \mathrm{TL}$ while another one was $180 \mathrm{TL}$ in August. This year in July without making reservation you went to a touristic area in Antalya in July where your friends accommodated. You have visited five hotels and got prices at the door. Hotels are almost same quality and have given prices for per person per night $120 \mathrm{TL}, 160 \mathrm{TL}, 175 \mathrm{TL}, 110 \mathrm{TL}$ and $180 \mathrm{TL}$ respectively. Which one is the acceptable price for you for your holiday? If your preference is different from these numbers please write it as others. We expect that people confuse and it will not be easy to give an answer this question because of given many different reference prices. Because people can remember last prices easily we also expect that they choose in the middle number of $110,120,160,175$, and $180 \mathrm{TL}$ and reply it as around $160 \mathrm{TL}$.

Average Turkish citizens income is around 400 Euro and 1 Euro $=3.2$ TL. In the research 26.4\% population's income is around average income level on Turkish citizens. Other income groups have also almost equal percentages in the whole group.

When has to decide something human always take a reference point even that point is irrelevant. Another truth is known that given two different reference prices (points) people usually take arithmetic average as expected price. What about if it will be given more reference prices for different months? We decided to search these questions answers and created hypotheses below.

Hypotheses: 
$\mathrm{H}_{0}$ : Given two different reference prices for same month do not affect expected price

$\mathrm{H}_{1}$ : Given two same reference prices for same month do not affect expected price

$\mathrm{H}_{2}$ : Given eight different prices for different months do not affect expected price

$\mathrm{H}_{3}$ : Tourism education has not effect on reference prices (anchoring effect)

$\mathrm{H}_{4}$ : Tourism related jobs have not effect on reference prices (anchoring effect)

\section{Empirical Results}

620 respondents' demographic facts are given at Table 1.

Table 1. Respondents' Demographic Characteristics

\begin{tabular}{|c|c|c|c|}
\hline & & Participant Count & $\%$ \\
\hline \multirow{3}{*}{ AGE } & $18-35$ & 428 & 69,0 \\
\hline & $36-49$ & 143 & 23,1 \\
\hline & 50 and upper & 49 & 7,9 \\
\hline TOTAL & & 620 & 100 \\
\hline \multirow[b]{2}{*}{ GENDER } & Women & 304 & 49,0 \\
\hline & Men & 316 & 51,0 \\
\hline TOTAL & & 620 & 100 \\
\hline \multirow{5}{*}{ INCOME } & $0-1,000$ & 166 & 26,8 \\
\hline & $1,001-2,000$ & 152 & 24,5 \\
\hline & $2001-3000$ & 157 & 25,3 \\
\hline & $3001-4000$ & 91 & 14,7 \\
\hline & 4.001 and upper & 166 & 26,8 \\
\hline TOTAL & & 620 & 100 \\
\hline \multirow[b]{2}{*}{ EDUCATION } & University student & 150 & 24,2 \\
\hline & $\begin{array}{c}\text { Non-university } \\
\text { student }\end{array}$ & 470 & 75,8 \\
\hline TOTAL & & 620 & 100 \\
\hline \multirow{2}{*}{$\begin{array}{c}\text { TOURISM } \\
\text { RELATION OF } \\
\text { PARTICIPANTS }\end{array}$} & $\begin{array}{l}\text { Having Tourism } \\
\text { Diploma }\end{array}$ & 202 & 32,6 \\
\hline & $\begin{array}{l}\text { Having Different } \\
\text { Diploma }\end{array}$ & 418 & 67,4 \\
\hline TOTAL & & 620 & 100 \\
\hline
\end{tabular}

As seen in Table 1, majority of the respondents' age is below $35(69 \%)$. There is gender equality. Almost $33 \%$ of the respondents have tourism diploma.

Table 2. Question 1 and Age Relation

\begin{tabular}{|c|c|c|c|c|}
\hline & \multicolumn{3}{|c|}{ Accepted Price (TL) } \\
\hline & & $<100$ & $101-200$ & $200>$ \\
\hline \multirow{3}{*}{ AGE } & $18-35$ & $39 \%$ & $49.2 \%$ & $20.8 \%$ \\
\hline & $36-49$ & $37.8 \%$ & $48.3 \%$ & $14 \%$ \\
\hline & 50 and upper & $53.1 \%$ & $32.7 \%$ & $14.3 \%$ \\
\hline
\end{tabular}


At the first question, it has been given $100 \mathrm{TL}$ and $200 \mathrm{TL}$ B\&B price as reference points. Except from 50 and upper age group (53.1\%), people made a calculation between given reference points and taken average. So majority of the people said the price should be between $101 \mathrm{TL}$ and $200 \mathrm{TL}$ which is acceptable for them. This result what we accepted. We also searched if there is a relation between gender and Question 1 and found that there is no statistically significant relation. Another interesting result is even the respondents informed that the holiday was happens to be at the same time with the national holiday (Bayram) and prices should be higher than normal days, they have ignored and anchored reference points which have been given by us.

Table 3. Question 1 and Income Level Relation

\begin{tabular}{|c|c|c|c|c|}
\hline & \multicolumn{3}{|c|}{ Accepted Price (TL) } \\
\hline & & $<100$ & $101-20$ & $200>$ \\
\hline \multirow{3}{*}{$\begin{array}{l}\text { INCOME } \\
\text { LEVEL }\end{array}$} & $0-1,000$ & $29.5 \%$ & $53 \%$ & $17.5 \%$ \\
\hline & $4,001>$ & $28.8 \%$ & $57.4 \%$ & $14.8 \%$ \\
\hline & TOTAL & $31.9 \%$ & $49.4 \%$ & $18.7 \%$ \\
\hline
\end{tabular}

In this table regarding Question 1, we have given lowest and highest income levels differences. As it could be seen in Table 3 both poor and rich respondents meet at acceptance of 101-200 TL (average) prices. If we add other income levels result do not change and majority of the responds gather at same point (49.4). We thought that reference point could be affected by occupancy so we have also searched it as tourism educated and non-tourism educated peoples' tendencies.

We assumed that tourism educated people have information that during national festivals (Bayrams) room prices be higher than normal times. So they should accept higher prices but we could not find this result. So there is no relation between tourism education and reference point bias. To search reference point bias we asked respondents currently if they work in a tourism related field or not. Again we failed to find relation between reference point and tourism related job. Another result which we have observed is no matter if participant is a university student or not.

We also applied Question 2 to search reference point like Question 1. But there is difference between Question 1 and Question 2 which given reference points were both $200 \mathrm{TL}$ in Question 2. We expected the respondents to write different and independent prices which differ from person to person.

Table 4. Question 2 and Age Relation

\begin{tabular}{|l|l|c|c|c|c|c|}
\hline \multicolumn{2}{|c|}{} & \multicolumn{5}{c|}{ Accepted Price (TL) } \\
\cline { 3 - 7 } \multicolumn{2}{c|}{} & $\mathbf{1 0 0}$ & $\mathbf{1 5 0}$ & $\mathbf{2 0 0}$ & $\mathbf{2 5 0}$ & $\mathbf{3 0 0}$ \\
\hline \multirow{3}{*}{ AGE } & $18-35$ & $7.5 \%$ & $9.1 \%$ & $\mathbf{4 4 . 5 \%}$ & $9.4 \%$ & $11.0 \%$ \\
\cline { 2 - 7 } & $36-49$ & $4.2 \%$ & $5.6 \%$ & $\mathbf{4 6 . 2 \%}$ & $12.6 \%$ & $9.8 \%$ \\
\cline { 2 - 7 } & 50 and upper & $4.1 \%$ & $16.3 \%$ & $\mathbf{4 0 . 8 \%}$ & $10.2 \%$ & $16.3 \%$ \\
\hline
\end{tabular}


Surprisingly, all age groups have met at 200 TL accepted prices. Question 2 gives same reference price (200 TL) as both friend experience and Ministry of Turkish Tourism and Culture. Question 1 gives two different reference prices $100 \mathrm{TL}$ and 200 TL respectively. There is no significant gender and income level differences for reference prices (Anchoring) bias.

Table 5. Question 2 and Tourism Education Relation

\begin{tabular}{|l|c|c|c|c|c|c|c|}
\hline \multicolumn{2}{|c|}{} & \multicolumn{6}{|c|}{ Accepted Price (TL) } \\
\cline { 2 - 7 } & 100 & 150 & 200 & 250 & 300 & $\begin{array}{c}\text { TOTAL } \\
\text { RESPON } \\
\text { DS }\end{array}$ \\
\hline $\begin{array}{l}\text { DO YOU HAVE } \\
\text { TOURISM DIPLOMA? } \\
\begin{array}{l}\text { IF SO ACCEPTED } \\
\text { PRICE... }\end{array}\end{array}$ & YES & $5.0 \%$ & $5.9 \%$ & $42.1 \%$ & $10.4 \%$ & $15.8 \%$ & 202 \\
& NO & $7.2 \%$ & $10.3 \%$ & $45.9 \%$ & $10.0 \%$ & $8.9 \%$ & 418 \\
\hline
\end{tabular}

Like Question 1, same results have been observed, regarding having tourism diploma and reference price (anchoring) bias. This result also coherence with tourism related job and university students (the control group) answers.

Lastly we wondered if we give different reference months and prices which month's price will be accepted as a reference price. So we asked Question 3.

Table 6. Question 3 and Age Relation

\begin{tabular}{|c|l|c|c|c|c|c|}
\hline \multicolumn{2}{|c|}{} & \multicolumn{5}{|c|}{ Accepted Price (TL) } \\
\cline { 3 - 7 } \multicolumn{2}{|c|}{} & $\mathbf{1 1 0}$ & $\mathbf{1 2 0}$ & $\mathbf{1 6 0}$ & $\mathbf{1 7 5}$ & $\mathbf{1 8 0}$ \\
\hline \multirow{3}{*}{ AGE } & $18-35$ & $\mathbf{2 5 . 3 \%}$ & $\mathbf{3 0 . 7 \%}$ & $23.2 \%$ & $13.1 \%$ & $5.6 \%$ \\
\cline { 2 - 7 } & $36-49$ & $\mathbf{2 3 . 8 \%}$ & $12.6 \%$ & $\mathbf{2 7 . 3 \%}$ & $21.7 \%$ & $5.6 \%$ \\
\cline { 2 - 7 } & 50 and upper & $\mathbf{2 6 . 5 \%}$ & $\mathbf{2 6 . 5 \%}$ & $20.4 \%$ & $16.3 \%$ & $8.2 \%$ \\
\hline
\end{tabular}

We can claim that if it will be given many reference prices, respondents' behaviour changes and reference price (anchoring) bias is gets weaker. However, reference price bias does not disappear. We can infer from the Table 6 that respondents tend to choose close prices (110 and $120 \mathrm{TL})$ to lower reference price $100 \mathrm{TL}$. Gender difference, income level difference and reference price relation could not be found.

There are slightly differences between tourism educated and non-tourism educated respondents. Tourism educated respondents has chosen $160 \mathrm{TL}(30.7 \%)$ as acceptable price while non-tourism educated people has chosen 120 TL $(32.1 \%)$ mostly. Same results are confirmed by respondents working in tourism related jobs, preferences $160 \mathrm{TL}(27.4 \%)$ and $120 \mathrm{TL}$ (29.3\%) respectively. Regarding being a university student (the control group) has also an effect on reference price 
(anchoring) bias. University students reference price is 120 TL (40.7\%) while nonstudents $160 \mathrm{TL}(25.7 \%)$. This could be explained by income level of university students.

\section{Results}

Reference price for sure has an effect on people. When companies advertise their prices, they should definitely give a reference prices to their potential customers but this reference prices should not exceed two prices. The best one is one reference price.

Our results coincidence with Kahneman's experiment results (2011, p.63). In that experiment Kahneman has given two different wrong birth dates for Hitler and asks which one is correct. Mostly respondents have chosen first reference number. So, the first is more likely to be believed. In our experiment, especially in question 2 respondents also choose first reference price rather than others.

We can make conclude that in marketing, friends' recommendation is more important than Ministry of Tourism and Culture's statistics. We can also state that on respondents' decisions. same reference price from two different sources is more effective than two different reference prices,

\section{References}

Ariely, D. 2010. Predictably Irrational, Harper Perennial Edition, ISBN 9780061353246.

Baker, M., Xin, P. and Wurgler, J. 2012. The effect of reference point prices on mergers and acquisitions. Journal of Financial Economics, Vol:106, pp. 49-71.

Barberis, N. and Thaler, R. 2002. A Survey of Behavioural Finance, pp. 1-77, www.nber.org/papers/w9222.pdf.

Becker-Peth, M. and Thonemann, W.U. 2016. Reference points in revenue sharing contracts - How to design optimal supply chain contracts. European Journal of Operational Research, Vol: 249, pp.1033-1049.

Birken, E.G. 2016. How Anchoring in Behavioral Economics Explains Your Irrational Money Choices, http://moneyning.com/money-beliefs/how-anchoring-in-behavioraleconomics-explains-your-irrational-money-choices/.

Burnam-Fink, M. 2015. Creating narrative scenarios: Science fiction prototyping at Emerge, Futures, Vol 70, pp. 48-55.

Chang Chuang-Chang, Ching-Hsiang Chao and Jin-Huei Yeh. 2016. The role of buy-side anchoring bias: Evidence from the real estate market, Pacific-Basin Finance Journal, Vol: 38, pp. 34-38.

Kahneman, D. 2011. Thinking, Fast and Slow, Penguin Books Ltd., London, ISBN 978-0141-03357-0, pp. 1-499.

Liu, E. and Hanauer, N. 2016. Complexity Economics Shows Us Why Traditional Economics Always Fails, http://evonomics.com/complexity-economics-shows-usthat-laissez-faire-will-never-work/.

Kozak, N. 2014. Bilimsel Araştırma: Tasarım, Yazım, Yayım Teknikleri, Detay Yayıncılık, Ankara, pp. 1-242. 
Does Human Stıck on Reference Prıce (Anchorıng Bıas)? A Socıal Experıment on Tourım Sector

104

Meub, L. and Proeger, E.T. 2015. Anchoring in social context. Journal of Behavioral and Experimental Economics, Vol: 55, pp. 29-39.

Ritter, J.R. 2003. Behavioral Finance, Pacific-Basin Finance Journal Vol. 11, pp. 429-437.

The Economist. 2009. Herbert Simon, http://www.economist.com/node/13350892. 